\title{
The Safety, Efficacy, and Cost Efficiency of Outpatient Treatment of Acute Deep Venous Thrombosis with Low Molecular Weight Heparin
}

THOMAS W. WAKEFIELD, M.D.

\begin{abstract}
Deep venous thrombosis (DVT) and pulmonary embolism (PE) remain significant heath care problems. Although standard unfractionated heparin effectively treats DVT and PE, low molecular weight heparins (LMWHs) have many theoretical advantages, including less bleeding potential, less thrombocytopenia, improved bioavailability, and more even pharmacokinetics. Additionally, LMWHs are given subcutaneously based on patient weight and do not need to be monitored by blood tests. Multiple studies have compared LMWH to standard heparin for treatment of DVT/PE. LMWHs have a lower risk for major bleeding, recurrent thromboembolic disease, and mortality rate for the treatment of DVT, whereas for PE treatment they are at least equivalent to standard heparin and more convenient. However, not all patients are candidates for such outpatient therapy. The ability to give LMWH subcutaneously and the lack of need for intensive blood monitoring allows for outpatient therapy.
\end{abstract}

Keywords: Deep venous thrombosis (DVT), pulmonary embolism (PE), low molecular weight heparin (LMWH)

Deep venous thrombosis (DVT) has been estimated to affect greater than 250,000 patients yearly. 1,2 Deep venous thrombosis and pulmonary embolism (PE) together are associated with 300,000 to 600,000 hospitalizations and as many as 50,000 deaths yearly, although others suggest an even higher yearly death rate. ${ }^{3}$ The cost of treating DVT is estimated to be between $\$ 1.0$ and $\$ 2.4$ billion per year, ${ }^{4}$ and DVT is responsible for increased mortality in the elderly. Thus DVT and PE together remain significant problems.

T.W.W., Professor of Surgery, Section of Vascular Surgery, Department of Surgery, University of Michigan, and Ann Arbor Veterans Administration Medical Center, Ann Arbor, MI.

Copyright (C) 2000 by Thieme Medical Publishers, Inc., 333 Seventh Avenue, New York, NY 10001, USA.

Tel.: +1(212) 584-4662. 0894-8046,p;2000,13,2,19,26,ftx,en; pvs00095 


\section{STANDARD UNFRACTIONATED HEPARIN}

The treatment of DVT and PE includes anticoagulation, intravenous unfractionated heparin followed by long-term oral anticoagulation. Adequate anticoagulation decreases the recurrence of venous thromboembolism (VTE) by $80 \%$ ( 29 to $47 \%$ untreated to 5 to $7 \%$ treated $^{5-8}$ ). In an analysis involving 25 studies with confirmed objective diagnosis of DVT and PE, the risk of fatal PE was very low, during $(0.4 \%)$ and after $(0.3 \%)$ adequate treatment for DVT, and during (1.5\%) and after $(0 \%)$ adequate treatment for PE. ${ }^{9}$ Standard unfractionated heparin is effective in treating DVT and PE.

However, the most important complication of anticoagulation therapy is bleeding. With standard intravenous unfractionated heparin, bleeding is seen in $11 \%$ of cases during the first 5 to 10 days of treatment. ${ }^{10}$ Major bleeding is noted between 0 and $7 \%$, whereas fatal bleeding has been noted between 0 and $2 \% .{ }^{11}$ Adding oral anticoagulation with an international normalized ratio (INR) between 2 and 3 results in an incidence of major bleeding of approximately $6 \%$ per year. Because of the bleeding associated with unfractionated heparin, low molecular weight heparins (LMWHs) were developed. Additional complications of heparin include thrombocytopenia, osteoporosis, and alopecia.

\section{LOW MOLECULAR WEIGHT HEPARIN}

Low molecular weight heparins are derived from the lower molecular weight range of heparin by chemical or enzymatic fragmentation. The mean molecular weight of LMWH is 4000 to $6500 \mathrm{~d}$, whereas the mean molecular weight of standard unfractionated heparin is 12,000 to $15,000 \mathrm{~d}$. The mean number of saccharide units for LMWH is 13 to 22 , whereas for standard heparin it is 40 to $50 . .^{12}$ Unfractionated heparin is large enough to make a threeway complex between thrombin, antithrombin, and heparin, and such a complex inhibits thrombin. This complex requires at least 18 saccharide units. Low molecular weight heparins are usually shorter than 18 saccharide units and, because of this, show less antithrombin activity. For inhibition of factor Xa, such a three-way complex is not required, allowing LMWHs to demonstrate more antifactor Xa activity. Each LMWH has its own antifactor Xa to antifactor IIa activity ratio, with most having a ratio between $2: 1$ to $4: 1$. This compares with a ratio of $1: 1$ for standard heparin. ${ }^{12}$

The advantages of LMWHs compared to standard heparin include a decrease in bleeding potential, less antiplatelet activity, a lower risk for heparin-induced thrombocytopenia, an improved pharmacokinetic profile due to reduced nonspecific plasma protein binding, decreased lipolysis, a half-life that is not dose dependent, more constant inhibition of antifactor Xa, less interference with physiologic protein $\mathrm{C}$ activation, less interference with platelet aggregation, less activation of the complement system, a lower risk of 
osteoporosis, and a lower level of fibrin monomer production. ${ }^{13}$ Because LMWH is dosed based on patient weight, LMWH therapy does not need to be monitored with blood tests of coagulation. Low molecular weight heparin is administered by subcutaneous injection and its excretion is primarily renal. The improved bioavailability of LMWHs and the persistence of their antifactor Xa action are likely key to their efficacy. ${ }^{14}$ Low molecular weight heparins are only partially reversed by protamine sulfate. ${ }^{15}$

\section{LOW MOLECULAR WEIGHT HEPARIN AND DEEP VENOUS THROMBOSIS}

Low molecular weight heparins have been recommended for DVT prophylaxis ${ }^{16}$ and treatment of venous thromboembolism. Treatment of DVT will be emphasized here. Level I studies and metaanalyses comparing LMWHs with unfractionated heparin for DVT and PE treatment have demonstrated LMWH to be at least as effective as, if not more effective than, unfractionated heparin. ${ }^{17-23}$ For DVT treatment, there is a lower risk for major bleeding, recurrent thromboembolic events, and even death with LMWH. ${ }^{24} \mathrm{~A}$ recent metaanalysis comprising 14 studies of 4754 patients revealed recurrent venous thrombotic complications at $4.3 \%$ for LMWH compared with $5.6 \%$ for standard unfractionated heparin (10 studies), mortality at $6.4 \%$ for LMWH compared with $8.0 \%$ for standard unfractionated heparin (11 studies), major hemorrhage at $1.3 \%$ for LMWH compared with $2.1 \%$ for standard heparin (14 studies), and similar findings when evaluating only more proximal DVT. ${ }^{25}$ For proximal above knee (AK) thromboses, thrombotic complications were noted in $4.8 \%$ for LMWH compared with $7.8 \%$ for heparin, major hemorrhage in $1.0 \%$ for $\mathrm{LMWH}$ versus $8.3 \%$ for heparin, and mortality in $5.4 \%$ for LMWH versus $8.3 \%$ for standard heparin.

\section{LOW MOLECULAR WEIGHT HEPARIN AND PULMONARY EMBOLISM}

For PE, studies have substantiated that LMWH is equivalent to and more convenient than standard unfractionated heparin. $22,26,27$ Three studies will be highlighted. A study of 1021 patients, 510 given Riviparin and 511 standard unfractionated heparin for DVT (73 to $74 \%$ ) and PE (26 to 27\%), found equivalent recurrent venous thromboembolism rates $(5.3 \%$ vs. $4.9 \%)$, major bleeding rates $(3.1 \%$ vs. $2.3 \%)$, mortality rates $(7.1 \%$ vs. $7.6 \%)$, and fatal PE rates $(0.6 \%$ vs. $0.6 \%)$. Importantly, the length of hospitalization was only 6.4 \pm 7.1 days for LMWH compared with $9.4 \pm 7.8$ days for standard heparin. ${ }^{22}$ A second study of 612 patients with clinically suspected PE (70\% with DVT) again revealed equivalence between the 304 treated with Tinzaparin and the 308 treated with standard heparin concerning combined outcomes of death, bleeding, and recurrent venous thromboembolism (5.9\% for LMWH, 7.1\% 
for standard heparin). ${ }^{26}$ Finally, a recent study of 200 patients presenting with acute proximal DVT ( 50 to $60 \%$ with asymptomatic PE) revealed a significant reduction in recurrent venous thromboembolism $(0 \%$ for $\mathrm{LMWH}, 6.8 \%$ for standard heparin), a reduction in mortality $(6.2 \%$ vs. $8.7 \%)$, a reduction in major bleeding (1.0\% vs. $1.9 \%)$, and a reduction in fatal pulmonary embolism $(0 \%$ vs. $1.0 \%) .{ }^{27}$

In summary, for DVT LMWH has been found to have a lower risk for major bleeding, a lower risk for recurrent thromboembolic disease, and a lower mortality rate. For the treatment of PE, LMWH is at least equivalent to standard heparin and certainly more convenient. Low molecular weight heparin therapy is dosed by patient weight and does not need to be monitored by coagulation tests, except in special circumstances such as renal failure. Because of the lack of monitoring necessary and the use of subcutaneous injections, outpatient treatment at home is a reality.

\section{CALF VEIN THROMBI}

One controversial area of therapy involves calf vein thrombi and the need to treat such thrombi. Approximately $20 \%$ of calf thrombi extend into the popliteal vein, and extension is associated with 40 to $50 \%$ rate of clinically detectable PE. Isolated calf thrombi have been associated with a $23 \%$ incidence of chronic venous insufficiency 12 months after diagnosis and an approximate $10 \%$ incidence of $\mathrm{PE}$ at presentation. ${ }^{28}$ Thus, most authorities today recommend full anticoagulation for isolated calf vein thrombosis, especially in the presence of any other risk factors for thrombosis. The ability to use outpatient LMWH will likely end this controversy because all calf vein thrombi may now be treated with LMWH and the justification for a full hospitalization for DVT treatment does not have to be made.

\section{ECONOMIC IMPACT OF LOW MOLECULAR WEIGHT HEPARIN}

The economic impact of using LMWH rather than standard unfractionated heparin for venous thromboembolism treatment has been investigated. Cost savings have ranged from greater than $\$ 300,000$ for 125 patients (or approximately $\$ 2500 /$ case) in the United States ${ }^{29}$ to approximately $\$ 4000$ (U.S. dollars) per case in Canada. ${ }^{30}$ Greater than a $60 \%$ cost reduction was found in Europe, Australia, and New Zealand, ${ }^{31}$ and once daily treatment with LMWH resulted in significant cost reductions in a Swedish study. ${ }^{32}$ Expanding indications, withholding LMWH therapy only to those patients with massive PE, a high risk for major or active bleeding, or phlegmasia and those patients already hospitalized for other diseases has resulted in more than $80 \%$ patient eligibility for home therapy and greater than $90 \%$ patient satisfaction. ${ }^{33,34}$ 


\section{PATIENTS NOT CANDIDATES FOR LOW MOLECULAR WEIGHT HEPARIN TREATMENT AS OUTPATIENT}

Thus, the use of LMWH appears to be possible in 80 to $90 \%$ of cases of DVT and PE with outpatient therapy in many. An area of potential concern is the nondiscriminative use of LMWH for all patients with DVT or PE, regardless of the presenting symptoms and signs. Patients who require more aggressive intervention as an inpatient include those with phlegmasia, young patients with extensive iliofemoral venous thrombosis who may benefit from thrombolysis or thrombectomy, and patients with extensive PE. Others who are not good candidates for outpatient therapy include patients with active bleeding or significant familial bleeding disorders in which heparin therapy may have to be reversed rapidly, those with significant leg edema, those already hospitalized, patients with liver dysfunction or renal insufficiency (creatinine $\geq 3.5$ $\mathrm{mg} / \mathrm{dL}$ or creatinine clearance $<30 \mathrm{~mL} / \mathrm{min}$ ), patients with severe obesity $(>120 \mathrm{~kg}$ ), and patients who are not capable (for personal, social, or travel reasons) to self-administer LMWH and follow up closely with their physician. ${ }^{35}$

\section{OUTPATIENT TREATMENT PROGRAM}

The outpatient treatment of venous thromboembolism with LMWH followed by oral anticoagulation requires more than just the writing of a prescription. To administer such a program, a physician must take responsibility for the outpatient program, pharmacy services are required to supply the drug, oral anticoagulation must be monitored and dose adjusted, visiting nurses must be arranged or some type of follow-up at home established, the patient must be instructed on self-injections, and orthotic services must be provided for the fitting of surgical support stockings. Such a program can be established, but many different resources must be brought together for such a program to be effective. ${ }^{36}$ It must also be remembered that LMWH is only a bridge to longer-term oral anticoagulant therapy.

\section{REIMBURSEMENT}

One area that still needs to be addressed is the area of reimbursement. Medicare and most insurance carriers will not pay for the outpatient procurement of LMWH by patients because LMWH is considered a self-injectable drug. This limits the ability to set up a totally outpatient program. Recent changes in Medicare reimbursement allow for outpatient coverage if the patient returns to an outpatient facility daily for injections. There is little doubt that eventually insurance providers will realize the tremendous cost savings that outpatient LMWH treatment for DVT and PE provides to the health 
care system. However, until that time patients must realize that they may be required to pay for their outpatient therapy out of pocket, or they will need to be hospitalized initially for a short time for insurance coverage to be provided.

\section{REFERENCES}

1. Coon WW, Willis PW 3rd, Keller JB. Venous thromboembolism and other venous disease in the Tecumseh community health study. Circulation 1973;48:839-846

2. Anderson FA Jr., Wheeler HB, Goldberg RJ, et al. A population-based perspective of the hospital incidence and case-fatality rates of deep vein thrombosis and pulmonary embolism. The Worcester DVT Study. Arch Intern Med 1991;151:933-938

3. Peterson KL. Acute pulmonary thromboembolism: has its evolution been redefined? Circulation 1999;99:1280-1283

4. Hull RD, Pineo GF, Raskob GE. The economic impact of treating deep vein thrombosis with low-molecular-weight heparin: outcome of therapy and health economy aspects. Haemostasis 1998;28(Suppl 3):8-16

5. Hull R, Delmore T, Genton E, et al. Warfarin sodium versus low-dose heparin in the long-term treatment of venous thrombosis. N Engl J Med 1979;301:855-858

6. Lagerstedt CI, Olsson CG, Fagher BO, Oqvist BW, Albrechtsson U. Need for long-term anticoagulant treatment in symptomatic calf-vein thrombosis. Lancet 1985;2:515-518

7. Kearon C, Hirsh J. Management of anticoagulation before and after elective surgery. N Engl J Med 1997;336:1506-1511

8. Hirsh J. Heparin. N Eng J Med 1991;324:1565-1574

9. Douketis JD, Kearon C, Bates S, Duku EK, Ginsberg JS. Risk of fatal pulmonary embolism in patients with treated venous thromboembolism. JAMA 1998;279:458-462

10. Hull RD, Raskob GE, Rosenbloom D, et al. Heparin for 5 days as compared with 10 days in the initial treatment of proximal venous thrombosis. N Engl J Med 1990;322:1260-1264

11. Levine MN, Raskob G, Landefeld S, Kearon C. Hemorrhagic complications of anticoagulant treatment. Chest 1998;114:511S-523S

12. Ageno W, Turpie AG. Low-molecular-weight heparin in the treatment of pulmonary embolism. Sem Vasc Surg 2000;13:189-193

13. Hirsh J. Low-molecular-weight heparin: a review of the results of recent studies of the treatment of venous thromboembolism and unstable angina. Circulation 1998;98:1575-1582

14. Sarret M. Low molecular weight heparins. Chemical and biological properties. In: Sarret M, Kher A, Toulemonde F, eds. Low Molecular Weight Heparin Therapy: An Evaluation of Clinical Trials Evidence. New York: Marcel Dekker; 2000:11-20

15. Kher A, Sarret M, Toulemonde F. Low molecular weight heparins and protamine neutralization. In: Sarret M, Kher A, Toulemonde F, eds. Low Molecular Weight Heparin Therapy: An Evaluation of Clinical Trials Evidence. New York: Marcel Dekker; 2000:456-457

16. Clagett GP, Anderson FA Jr., Geerts W, et al. et al. Prevention of venous thromboembolism. Chest 1998;114:531S-560S

17. Leizorovicz A. Comparison of the efficacy and safety of low molecular weight heparins and unfractionated heparin in the initial treatment of deep venous thrombosis. An updated meta-analysis. Drugs 1996;52:30-37

18. Siragusa S, Cosmi B, Piovella F, Hirsh J, Ginsberg JS. Low-molecular-weight heparins and unfractionated heparin in the treatment of patients with acute venous thromboembolism: results of a meta-analysis. Am J Med 1996;100:269-277

19. Hull RD, Raskob GE, Pineo GF, et al. Subcutaneous low-molecular-weight heparin compared with continuous intravenous heparin in the treatment of proximal-vein thrombosis. N Engl J Med 1992;326:975-982 
20. Levine M, Gent M, Hirsh J, et al. et al. A comparison of low-molecular-weight heparin administered primarily at home with unfractionated heparin administered in the hospital for proximal deep-vein thrombosis. N Engl J Med 1996;334:677-681

21. Koopman MM, Prandoni P, Piovella F, et al. Treatment of venous thrombosis with intravenous unfractionated heparin administered in the hospital as compared with subcutaneous low-molecular-weight heparin administered at home. The Tasman Study Group. N Engl J Med 1996;334:682-687

22. The Columbus Investigators. Low-molecular-weight heparin in the treatment of patients with venous thromboembolism. N Engl J Med 1997;337:657-662

23. Lensing AW, Prins MH, Davidson BL, Hirsh J. Treatment of deep venous thrombosis with low-molecular-weight heparins. A meta-analysis. Arch Intern Med 1995;155: 601-607

24. Lensing AW, Prandoni P, Prins MH, Buller HR. Deep-vein thrombosis. Lancet 1999; 353:479-485

25. van den Belt AG, Prins MH, Lensing AW, et al. Fixed dose subcutaneous low molecular weight heparins versus adjusted dose unfractionated heparin for venous thromboembolism. Cochrane Database of Systematic Reviews [computer file]. (2): C0001100, 2000. 20257683

26. Simonneau G, Sors H, Charbonnier B, et al. A comparison of low-molecular-weight heparin with unfractionated heparin for acute pulmonary embolism. The THESEE Study Group. N Engl J Med 1997;337:663-669

27. Hull RD, Raskob GE, Brant RF, et al. Low-molecular-weight heparin vs heparin in the treatment of patients with pulmonary embolism. American-Canadian Thrombosis Study Group. Arch Intern Med 2000;160: 229-236

28. Meissner MH, Caps MT, Bergelin RO, Manzo RA, Strandness DE Jr. Early outcome after isolated calf vein thrombosis. J Vasc Surg 1997;26:749-756

29. Groce JB 3rd. Patient outcomes and cost analysis associated with an outpatient deep venous thrombosis treatment program. Pharmacotherapy 1998;18:175S-180S

30. Hull RD, Raskob GE, Rosenbloom D, et al. Treatment of proximal vein thrombosis with subcutaneous low-molecular-weight heparin vs intravenous heparin. An economic perspective. Arch Intern Med 1997;157:289-294

31. van den Belt AG, Bossuyt PM, Prins MH, Gallus AS, Buller HR. Replacing inpatient care by outpatient care in the treatment of deep venous thrombosis-an economic evaluation. TASMAN Study Group. Thromb Haemost 1998;79:259-263

32. Lindmarker P, Holmstrom M. Use of low molecular weight heparin (dalteparin), once daily, for the treatment of deep vein thrombosis. A feasibility and health economic study in an outpatient setting. Swedish Venous Thrombosis Dalteparin Trial Group. J Intern Med 1996;240:395-401

33. Wells PS, Kovacs MJ, Bormanis J, et al. Expanding eligibility for outpatient treatment of deep venous thrombosis and pulmonary embolism with low-molecular-weight heparin: a comparison of patient self-injection with homecare injection. Arch Intern Med 1998; 158:1809-1812

34. Harrison L, McGinnis J, Crowther M, Ginsberg J, Hirsh J. Assessment of outpatient treatment of deep-vein thrombosis with low-molecular-weight heparin. Arch Intern Med 1998;158:2001-2003

35. Dunn AS, Coller B. Outpatient treatment of deep vein thrombosis: translating clinical trials into practice. Amer J Med 1999;106:660-669

36. Proctor MC, Greenfield LJ, Froehlich JB, Montgomery P, Wakefield TW. Limitations and value of ambulating treatment of DVT. American Venous Forum, February 1999, Dana Point, CA

*The Expert Commentary and Last Word for this article can be found on pp. 121-125. 
